\title{
Organization of Innovative Project Management on the Base of Multimode Modeling of Probabilities Mixture of Labor Processes
}

\author{
Usanov A.I. \\ Kazan national research technical university named after A.N.Tupolev, Kazan, 420103, Russia \\ Email address: usanov.usanova@yandex.ru
}

Usanova D.S.

Kazan Federal University, Institute of Management, Economics and Finance, Kazan, 420008, Russia

\section{Doi:10.5901/mjss.2014.v5n24p20}

\begin{abstract}
In this study we suggest an approach to the organization of innovative projects management based on multimode modeling of probabilities mixture of labor processes. The proposed model allows managers to optimize the control actions influence on separate labor processes for achieving the innovative project result in the minimum time. Organization of management on the basis of the proposed model minimizes the risks of management bureaucracy and labor processes uncontrollability.
\end{abstract}

Keywords: innovative projects management, multimode modeling, probabilities mixture, labor, labor collective management

\section{Introduction}

A labor collective management in the area of innovative industries requires a coordination of plurality of heterogeneous labor processes [1] that often leads to the uncertain result. Innovative labor processes succeeds only with a certain probability over a certain time. Well as, the innovative labor process may negate positive result - failure. In this case, all associated labor processes will also be doomed to a negative result.

Innovative production process is complex because labor processes have the following properties:

- they are stochastic relative to the labor results;

- they are heterogeneous, but their effectiveness depends on the results of other labor processes;

- the results of individual innovative work processes is difficult to estimate in economic terms;

- speed and quality of work in a complex manner dependent on the amount of allocated resources, this means, that the allocation of additional resources does not necessarily lead to a proportional increase in the efficiency of the labor process.

Specified features of work on innovative projects require using the probability theory methods and the fuzzy sets theory [2], [3], [4], [5], [6], [7] for the effective organization of innovative projects management.

\section{Methods for Efficient Management of Labor Processes in the Performance of Innovative Projects}

The purpose of the work is to develop methods for efficient management of labor processes in the performance of innovative projects.

The main objective of the innovative project effective management is to achieve results in the minimum time while limiting on resources.

It should be noted that the achievement of the result (negative conclusion is the result too) on an infinite time interval is the certain event [9].

The control action is to allocate resources between labor processes. All industrial resources will be considered as costs. The distribution of costs between the salaries, equipment and production facilities will be considered optimal.

For innovative production, it is important to consider the impact of external influences. The main external influences should include scientific and technical progress and socio-economic environment. If necessary, a list of external influences can be expanded. External influences lead to the appearance of fluctuations that govern the innovative production process [10] regardless of an enterprise organizational structure. For example, fluctuations due to external 
influences may lead to faster result reception due to scientific and technological progress, or, conversely, slow down due to staff socio-economic problems diversion.

To achieve the main objectives of management, stated above, it is necessary to provide a "responsive" operative diagnostics of the labor processes. When interpreting the results of such a diagnosis, it should take into account the inertia of the production process, that is, an additional allocation of resources would increase the efficiency of the labor process, but after a while. Inertia increases in proportion to the complexity of the organizational structure and ranges from a few weeks for independent working groups, to several months for companies with multi-level management hierarchy.

Diagnosis should provide management bodies with sufficient information to manage an innovative project: time coordination of various work processes of results obtaining, qualitative and quantitative agreement between the results, ensuring the continuity of the results of various labor processes and so.

At the bifurcation points the labor process is at a crossroads and fairly the slightest control action to change the "direction" of the work. If the at the bifurcation point there is no impact of management bodies, the choice is based on the fluctuations, as a result of external influences. It should be noted that this "self-government" is not always a bad thing. For example, a bifurcation based on the achievements of scientific and technological progress is more preferable than running management "material" preferences.

Redundancy of diagnostic information usually reduces production efficiency on the one hand, increases the complexity reporting and enterprise resources diverted from the main production, and on the other hand management bodies can not cope with large volumes of data. Both effects lead to inadequate management, i.e. management without the production inertia considering and the workflows bifurcation points skipping.

If management bodies do not take into account the labor process inertia, then, as a rule, there is a "bureaucratic response" in the management structure. In this case, the control develops approximately in the following sequence:

- control actions become greater and more powerful;

- labor processes do not have to respond to control actions and form the inner resources to interact with management;

- increases the labor processes inertia and reporting is no longer reflect the real situation of labor processes and formed "in favor of" superiors;

- at a management occurs a mismatch in representations about the labor process and observed results;

- to resolve this contradiction control actions become greater and more powerful;

- etc.

As a result of this process, the organizational structure of the company plunges "in itself" and begins to manage itself. Production processes at the same time become virtually unmanageable. This means that labor processes are controlled by "informal" leaders [9] and evolve according to the fluctuations caused by external influences, which now also include enterprise management bodies. The main disadvantage of this model is inadequate distribution of resources that concentrated without considering to the innovative project main goal. This leads to the closure of labor processes and a lack of continuity results because the results usefulness for the results generating labor process, and not to the entire innovation project, comes to the forefront. For example, departments refuse to transmit information to each other, the responsibility is shifted to each other, the results are made in uncomfortable for other consumers way.

Unfortunately, this model is a major attractor of large innovative enterprises. Exit from this state is a structural separation of a large production into smaller, or the management structure reorganization based on the innovative production features. Is why for effective innovative project management is necessary to provide the required state and development of the labor process, and not by the management of labor processes.

\section{Method (Multimode Models)}

One of the most promising approaches to the description of complex systems, allowing to identify the type and parameters of external stabilizing effects, is based on a multimode models [13]. Multimode models allow us to highlight system modes of state and behavior based on it's functional tasks and structural interactions [14]. Structure of the multimode model remains the same in different types of system architecture at accepted level of functional specification. In this case, the task is to optimize the characteristics of the modes of state and behavior.

In other words, the construction of a multi-mode model of innovative project management allows managers to focus on the labor process functionality and development. This does not require the study and control of internal mechanisms of the labor process.

Description of the state and behavior of complex systems in the framework of multimode models involves an 
allocation of "the modes of state" and "the modes of behavior" in the complex system. Each $m$-th modes of state ensemble corresponds the time ${ }^{\Delta \tau_{m}}$, during which the structure of the modes of state remains unchanged or changes in this structure are negligible. Each $m$-th modes of behavior corresponds the time ${ }^{\Delta T_{m}}$, during which the changing in the structure of modes of state occurs. For management system the time $\Delta \tau_{m}$ determines by the labor processes inertia. Time $\Delta T_{m}$ determines by the time, during which the system can adapted to a control action. It is clear that it is pointless to affect the labor processes more often. A large number of uncoordinated control actions during the time $\Delta T_{m}$ would lead to unpredictable changes in the state of labor processes. However, lack of control during the time $\Delta T_{m}$ can cause unpredictable state, formed under the influence of external fluctuations.

Thus, an effective management system should provide itself with diagnostic information during the time $\Delta \tau_{m}$, and realize control action during the time $\Delta T_{m}$. Control action can be directed to the preservation of state, i.e. to the resistance to external influences. Or, conversely, to overcome the "stagnation" management can lead the labor processes out of equilibrium state for forming a new efficient structure under external influences.

In multimode model external effects may be divided into two types: random fluctuations $\gamma\left(\Delta T_{m}\right)$ and deterministic control $\varphi\left(\Delta T_{m}\right)$. The process of developing an innovative project can be described as a function of the probability of achieving the result $F=F(t, \varphi, \gamma)$. Probability of achieving results in the selected $m$-th ensemble of the state of modes can be described by a probability density:

$$
F=F\left(\chi_{j}, \varphi\left(\Delta T_{m}\right), \gamma\left(\Delta T_{m}\right), \Delta \tau_{m}\right)
$$

here $\chi_{j}$ - set of parameters describing the state of an innovative project in the interval $\Delta \tau_{m}, \gamma\left(\Delta T_{m}\right)-$ random fluctuations, $\varphi\left(\Delta T_{m}\right)$ - deterministic control.

Each state is determined by the state of the labor process. Thus, the function of the probability of achieving the result is a mixture of the probability of result achievement in separate labor processes:

$$
F\left(\chi_{j}, \varphi\left(\Delta T_{m}\right), \gamma\left(\Delta T_{m}\right), \Delta \tau_{m}\right)=\sum_{i=1}^{N} \rho_{i}\left(\chi_{j}, \varphi\left(\Delta T_{m}\right), \gamma\left(\Delta T_{m}\right), \Delta \tau_{m}\right)
$$

where $\rho_{i}\left(\chi_{j}, \varphi\left(\Delta T_{m}\right), \gamma\left(\Delta T_{m}\right), \tau_{m}\right)$ - the probability of achieving parameters $\chi_{j}$ in $i$-th labor process during the time $\Delta \tau_{m}, N$ - the number of functionally separate labor processes.

\section{Result}

The resulting probability mixture determined by the structure of enterprise and the functional needs of the innovation project. The allocation of resources is optimized by control actions $\varphi\left(\Delta T_{m}\right)$. Generalized control function can be represented as the cost of the labor process implementing. Resources limits are imposed on the realization of the entire innovation project:

$\sum_{i=1}^{N} \varphi_{i}=C$

$\sum_{i=1}^{N} \varphi_{i}\left(\Delta T_{m}\right)=C\left(\Delta T_{m}\right)$

where $\mathrm{C}$ - an amount of resources allocated to the project.

Selection of deterministic control functions $\varphi_{i}\left(\Delta T_{m}\right)$ allows to get required set of probabilities $\rho_{i}$ of the labor process implementing. Amount of resources determines the ability to manage the change in the probability distribution in the mixture $\sum_{i=1}^{N} \rho_{i}\left(\chi_{j}, \varphi\left(\Delta T_{m}\right), \gamma\left(\Delta T_{m}\right), \Delta \tau_{m}\right)$.

The evolution of the work on the innovative project in time involves the growth of the total probability of achieving results $F=F(t, \varphi, \gamma)$. As a result, an infinite time interval receiving the result becomes certain event:

$F(t, \varphi, \gamma)=1$.

Figure 1 shows the evolution of the mixture of probabilities $\rho_{i}$ in time.

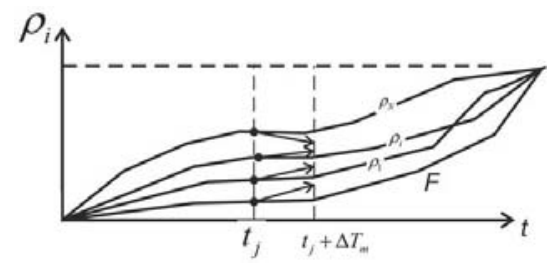

Fig. 1 The distribution function of the random time point of completion of the innovative project, which reflects the 
evolution of the innovative project

When such a management model is implemented, concrete state depends on the values of probability of obtaining results with parameters $\chi_{j}$ for each of the labor process.

Labor process does not have the Markov property and develops under the influence of random and deterministic effects from state with parameters $\chi_{j}$. It is obvious that at least a deterministic control determined on the basis of the experience of previous states. Is why the following implementation of the ensemble of the modes of state (new probabilistic mixture) is determined by an appropriate vector of effects. The control problem is reduced to control of the speed of change of the probabilities $\rho_{i}$, so as to ensure the maximum growth of likelihood of achieving the the result of the innovative project: $\frac{d F}{d t} \stackrel{t \rightarrow \min }{\longrightarrow} \max$.

Diagnosis should allow to evaluate the state of the system during the time $\Delta \tau_{m}$, and during the time $\Delta T_{m}$ accumulate statistics allowing to form an adequate set of control actions $\varphi\left(\Delta T_{m}\right)$. The next set of control actions should be ready for the next period $\Delta T_{m}$, etc.

\section{Conclusion}

The proposed multi-mode model for the probabilistic mixture of labor processes:

1) to optimize the control action to achieve the result of the innovative project in the shortest possible time;

2) takes into account the labor processes inertia and avoids bureaucratization of management;

3) allows to develop a management strategy based on random external influences;

4) allows to control not by the labor processes, but their states and development what has a positive effect on the creative atmosphere in the team and reduces the load on the top level of management.

\section{References}

Josef Blasini, Susanne Leist, (2013). Success factors in process performance management, Business Process Management Journal, Vol. 19 Iss: 3, pp.477 - 495.

Bowers John, Khorakian Alireza, (2014). "Integrating risk management in the innovation project", European Journal of Innovation Management, Vol. 17 Iss: 1, pp.25 - 40.

Chang S.S.L., (1977). "Application of fuzzy set theory to economics", Kybernetes, Vol. 6 Iss: 3, pp.203 - 207.Selçuk Perçin, (2008). "Fuzzy multi-criteria risk-benefit analysis of business process outsourcing (BPO)", Information Management \& Computer Security, Vol. 16 Iss: 3, pp.213 - 234.

Shigabieva A.M., Safiullin L.N., Mazitov V.M., Saipullaev U.A. Some methodological foundation of an innovation theory. Life Science Journal 2014; 11(6s): 388 - 391.

Peter Byrne, (1995). "Fuzzy analysis: A vague way of dealing with uncertainty in real estate analysis?", Journal of Property Valuation and Investment, Vol. 13 Iss: 3, pp.22 - 41.

Jack Allen, Sukanto Bhattacharya, Florentin Smarandache, (2003). "Fuzziness and funds allocation in portfolio optimization", International Journal of Social Economics, Vol. 30 Iss: 5, pp.619-632.

Panasyuk M.V., Pudovik E.M., Sabirova M.E. Problems of labor market of modern Russia in conditions of stable economic growth. Life Science Journal 2014; 11(6s): 487 - 489.

David P. Lepak, Jennifer A. Marrone, Riki Takeuchi (2004). The relativity of HR systems: conceptualising the impact of desired employee contributions and HR philosophy, International Journal of Technology Management 2004 - Vol. 27, No.6/7 pp. 639 - 655.

Orlova, M., Khafizova, A. (2014). The tax component of innovative activity assessment in the Russian federation. Life Science Journal, 11 (11), pp. 328-333.

Oksanen Kaisa, Ståhle Pirjo, (2013. "Physical environment as a source for innovation: investigating the attributes of innovative space", Journal of Knowledge Management, Vol. 17 Iss: 6, pp.815 - 827.

Terje Slåtten, Göran Svensson, Sander Sværi, (2011). "Empowering leadership and the influence of a humorous work climate on service employees' creativity and innovative behaviour in frontline service jobs", International Journal of Quality and Service Sciences, Vol. 3 Iss: 3, pp.267 - 284.

Ablaev I.M., Khovanskaya E.S. Essence and Economical Substance of Innovative Cluster in Territorially Localized Business System// Mediterranean Journal of Social Sciences.- Vol.5, No12, (2014)-pp.159 - 162.

MP Danilaev, V. Afanasyev, YE Polish (2011). Generalized multimode models, Generalized multimode model for analysis and synthesis of electronic, quantum systems and fractal structures. LAP LAMBERT Academic Publishing.

Alan Flook, (1996) "Fractals", Sensor Review, Vol. 16 Iss: 3, pp.42 - 47.

Sadriev A.R., Pratchenko O.V. Idea Management in the System of Innovative Management// Mediterranean Journal of Social Sciences.Vol.5, No12, (2014)-pp.155 - 158. 